\title{
HAKANI E A CAMPANHA CONTRA O INFANTICÍDIO INDÍGENA: PERCEPÇÕES CONTRASTANTES DE HUMANIDADE E PESSOA NA AMAZÔNIA BRASILEIRA*
}

Fernando Santos-Granero

No dia 5 de maio de 2008, Andreabrasil31, uma usuária brasileira do YouTube, postou um vídeo intitulado "Crianças enterradas vivas na Amazônia Hakani" junto com um link para a página do vídeo na internet: www.hakani. org (Andreabrasil31 2008). O vídeo, de 50 segundos, começa com uma advertência aos espectadores de que "contém nudez indígena e algumas imagens perturbadoras". Segue-se um close em terra vermelha sendo remexida como se alguém enterrado debaixo dela estivesse se debatendo na tentativa de emergir de volta à superfície, depois a tomada de uma pessoa batendo com os pés a terra solta, deixando-a firme. Vemos então uma indígena idosa contando o que aconteceu: "Aí ela cavou um buraco e colocou o bebê dentro dele. Jogou terra por cima e bateu a terra. O bebê chorou a noite toda e morreu no dia seguinte". Intercaladas com as imagens da velha mulher, vemos tomadas fragmentadas de um bebê sendo enterrado vivo. Em seguida, vemos um homem indígena afirmando: "O menino que foi enterrado vivo era o filho da minha irmã. Eu fiquei tão triste que o enterraram. Eu queria morrer com ele". Novamente, as imagens do narrador se alternam com tomadas rápidas do enterro de um bebê, incluindo uma muito chocante de um homem jogando terra no rosto parcialmente coberto do bebê. A isto se segue a imagem de uma mulher indígena nua segurando uma criança nos braços e dizendo: "Estamos fazendo este filme por causa das crianças". O vídeo se encerra com uma voz em off declarando que "Todo ano, centenas de crianças são enterradas vivas na Amazônia. Esta é a história de uma que sobreviveu: Hakani".

Como se revelou mais tarde, o vídeo era o trailer de um filme de 35 minutos chamado Hakani, produzido pela ONG brasileira ATINI — Voz pela Vida para divulgar sua campanha contra o infanticídio indígena na Amazônia brasileira. O filme encena o que se apresenta como a história verdadeira de Hakani, uma menina suruwaha, e seu irmão mais velho Niawi, ambos 
acometidos por uma doença neuromotora mais tarde diagnosticada como causada por hipotireoidismo. De acordo com a história, publicada em duas partes no Correio Braziliense (Abreu 2007a, 2007b), membros da maloca na qual a família de Hakani morava consideraram que as crianças tinham sido atacadas por um espírito da floresta e eram a causa de muitos de seus infortúnios. Eles teriam pressionado os pais a matar as crianças; estes, sem coragem, haviam cometido suicídio. Membros da maloca teriam então obrigado o irmão mais velho das crianças a matá-las. Segundo a narrativa, o irmão havia batido nelas com um pau até caírem inconscientes, pondose a enterrá-las numa cova rasa. Contam que Niawi não reagiu e morreu. Hakani chorou e, segundo dizem, foi salva pelo irmão do meio, que a criou por três anos, até que a entregou a um posto missionário próximo, onde ela recebeu cuidados e mais tarde foi adotada pelos missionários evangélicos Márcia e Edson Suzuki.

Foi supostamente esta experiência que levou os Suzuki a fundarem a ATINI - Voz pela Vida, uma ONG que, de acordo com a página Hakani na internet, reúne uma ampla gama de líderes indígenas, antropólogos, linguistas, advogados, políticos e educadores que buscam aumentar a conscientização sobre o infanticídio no Brasil. Seu objetivo principal é a aprovação do Projeto de Lei 1057, submetido ao Congresso Federal brasileiro em maio de 2007 pelo deputado federal Henrique Afonso. A proposta foi chamada de Lei Muwaji em homenagem a Muwaji, uma indígena suruwaha que se recusou a matar sua filha Iganani, que sofria de paralisia cerebral.

O trailer de Hakani, que parecia retratar atos da vida real e não trazia nenhum esclarecimento indicando que se tratava de um docudrama, causou alvoroço na internet, provocando uma enxurrada de comentários negativos e ataques racistas que variavam de "Repugnante", "Isso é muito doente" a "Tá certo. Então se livrem dessas tribos indígenas". Dali em diante, o fato de a história de Hakani apresentada pela ATINI ser ou não baseada em fatos reais passou a ser irrelevante: ao misturar o real com o virtual, a história se tornou verdadeira pelo mero fato de ter sido encenada como um filme e ter produzido efeitos reais em seus espectadores. A discussão do Projeto de Lei Muwaji incitou comentários negativos semelhantes contra os povos indígenas amazônicos em rádios e jornais nacionais e regionais. Contudo, tanto o filme quanto o Projeto de Lei também levantaram alguns assuntos muito importantes ligados a direitos humanos, diferenças culturais, moralidades alternativas e autonomia indígena. Esse debate adquiriu a forma de um confronto entre defensores de direitos humanos e advogados do direito à diferença cultural. Com igual paixão, ambas as partes mobilizaram uma 
variedade de argumentos em defesa de suas posições. Ausente da discussão, no entanto, estava o ponto de vista indígena amazônico: o debate foi levado adiante em termos ocidentais e por meio de argumentos ocidentais, emergindo como um ato de "purificação" semelhante ao discutido por Bruno Latour (1993) em seu livro Jamais fomos modernos.

Neste artigo, proponho reparar esta situação ao examinar o modo como as concepções indígenas amazônicas de "pessoa" e "humanidade" diferem das prevalecentes nas sociedades ocidentais. Em contraste com o isomorfismo presumido entre as noções de pessoa e humanidade, hipótese que informou muito sobre a religião e a filosofia ocidentais desde o começo da era cristã nas ontologias ameríndias estas duas condições são consideradas como estados independentes de existência, que podem ou não se manifestar conjuntamente. Enquanto do ponto de vista indígena amazônico a condição de pessoa é um atributo de todos os seres vivos, a humanidade é uma qualidade que diz respeito a apenas um tipo de ser, caracterizado como "pessoas de verdade". Não somente os indígenas amazônicos consideram estes estados como autônomos - com isso concebendo a existência tanto de pessoas não humanas quanto de humanos não pessoas - como também consideram pessoa e humanidade condições adquiridas em processos determinados pela natureza da interação social, em sentido amplo, ou seja, incluindo a interação com pessoas não humanas, como animais, plantas e objetos.

Exploro a singularidade destas concepções ameríndias por meio de uma série de "instantâneos" etnográficos - histórias de campo, anedotas e reflexões extraídas de etnografias muito conhecidas - analisadas à luz dos recentes desenvolvimentos na antropologia amazônica. Cabe advertir os leitores, contudo, de que algumas dessas etnografias datam de muitas décadas e não necessariamente refletem práticas indígenas do presente. Ainda mais importante é registrar que muitos povos indígenas da Amazônia abandonaram essa prática há muitos anos, como decorrência do cada vez mais intenso contato com a sociedade nacional, que essa prática é de fato rara e que, onde ainda persiste, é tema de muita discussão entre homens e mulheres indígenas. Na próxima seção, discuto os debates sociais e políticos animados pelo trailer de Hakani e pelo Projeto de Lei Muwaji até agosto de 2009, quando terminei de escrever este artigo. Do meu ponto de vista, são debates que iluminam mais as visões de mundo e os processos intelectuais do Ocidente do que a questão do infanticídio indígena na Amazônia. Concluo associando-me a Latour (1993:103) no seu chamado por uma "antropologia simétrica", que expõe as falácias do pensamento ocidental e "se abstém de fazer qualquer declaração apriorística sobre o que pode distinguir Ocidentais de Outros". 


\section{A origem das pessoas humanas e não humanas}

Com algumas variações relevantes, as cosmologias amazônicas sustentam que, desde os primórdios, todos os seres eram pessoas humanas que viviam em conjunto, sujeitas às mesmas regras da vida social. Cada um, no entanto, já possuía os traços identitários singulares que caracterizam as espécies ou os objetos que representam hoje. A mulher-aranha era uma hábil tecelã de redes; a pessoa-tabaco era um velho pajé; e a pessoa-vespa era um guerreiro feroz, virtuoso no arremesso de lanças. As cosmologias indígenas amazônicas expõem uma variedade de motivos pelos quais esta situação chegou ao fim (ver Santos-Granero 1998; Civrieux 1997; López 2006). O que importa aqui é que esse período se encerrou com a transformação de algumas dessas pessoas dos primórdios nos animais, nas plantas e nos objetos que existem hoje. Esses outrora humanos ainda possuem, contudo, uma alma de forma humana, sendo considerados por este motivo "pessoas".

A premissa de que todos os seres vivos compartilham uma ancestralidade humana é expressa claramente por Michael Brown (1986:54-55) em sua caracterização da cosmologia awajun (aguaruna) como uma ordem antropocêntrica:

No cerne da visão de mundo aguaruna estão crenças sobre a natureza e as propriedades das almas. Seres humanos, animais, plantas e alguns objetos inanimados têm alma. As almas de seres humanos são comumente denotadas pela palavra wakán; as almas de plantas, animais e coisas são mais correntemente apontadas pela palavra aents, literalmente "pessoa". Uma wakán é uma espécie de ser humano que continua a existir depois da morte. A aents, ou a "pessoa" de uma planta, animal ou coisa, é uma entidade antropomórfica que normalmente está oculta na forma exterior do ser ou da coisa, mas que pode se revelar para o observador humano instruído. Gloso tanto wakán como aents como "alma" porque, até onde pude estabelecer, elas se referem a um conceito idêntico - isto é, uma essência permanente e oculta que, quando se torna visível, tem a forma e as características de um ser humano.

Nas sociedades indígenas da Amazônia, pessoalidade é um atributo daqueles seres que possuem "alma" ou "vitalidade" — muitas vezes concebido como um de vários componentes espirituais do eu e o único que pode se separar do corpo de uma pessoa (ver, porém, Vilaça 1992, 2005 e Werlang 2006, para noções indígenas mais complexas de alma). É a posse de tal alma que confere a todos os seres vivos a capacidade do pensamento, da comunicação e da ação significativa. 
Nem todas as pessoas, entretanto, são consideradas humanas. Embora admitindo que humanos, a maior parte das plantas, animais e alguns fenômenos naturais sejam pessoas (aents) que possuem alma (wakán), os Achuar outro povo que fala o jivaro - consideram que "apenas os humanos são "pessoas completas" (penke aents), já que a sua aparência corresponde plenamente à sua essência" (Descola 1996a:93). Humanidade e pessoalidade, portanto, não são concebidas como qualidades isomórficas. A era mítica da indiferenciação entre todos os seres vivos chegou ao fim com a separação entre pessoas humanas e não humanas ou, para falar em termos ameríndios, entre "pessoas" e "pessoas de verdade".

A face visível de tais diferenças veio acompanhada de doença, predação e morte. A despeito de sua ancestralidade humana comum, humanos, animais, plantas, espíritos e objetos começaram a caçar uns aos outros (ver, por exemplo, Vilaça 1992:49-51). Isto é explicado pela muito difundida noção ameríndia de que a força vital que energiza todos os seres vivos é fixa, finita, mal distribuída e em constante circulação. Por este motivo, todas as pessoas vivas - sejam elas humanas ou não - competem entre si para acumular tanta energia vital quanto seja possível. Como sugeri em outro lugar, é esta competição pelas forças vitais que caracteriza as sociedades ameríndias como baseadas em uma "economia política de vida" (Santos-Granero 2009a). A ancestralidade comum e a pessoalidade compartilhada justificam o respeito que indígenas da Amazônia demonstram em relação a todos os seres humanos. Este respeito é fortalecido pela característica "perspectivista" das cosmologias indígenas da Amazônia, que sustenta que todos os seres vivos se veem como humanos ao enxergarem outras espécies como seus opostos estruturais, sempre envolvidos em relações entre presa e predador (Viveiros de Castro 1998; Stolze Lima 1999). A competição por forças vitais e a predação generalizada constituem, entretanto, uma ameaça permanente à integridade humana, envolvendo seres humanos, como veremos a seguir, numa constante luta para preservar sua humanidade e sua pessoalidade dos ataques de seus competidores não humanos.

\section{As incertezas da concepção humana}

Essa luta começa com a concepção. Da perspectiva indígena amazônica, a humanidade não é garantida pelo fato de se nascer de mãe humana. As mulheres podem ser fecundadas por animais, espíritos e outras pessoas não humanas que visam avançar os interesses da sua espécie em detrimento dos de seus competidores. Mulheres grávidas e suas famílias nem sempre estão atentas a essas ocorrências. E como a possibilidade de uma filiação monstruosa 
não é incomum, não há nenhuma certeza de que a mulher dará à luz um bebê humano até que ele tenha nascido (ver, por exemplo, Gow 1997:48). Em muitas sociedades ameríndias, o nascimento de gêmeos é considerado uma manifestação de fecundação não humana, como Kenneth M. Kensinger (1995:210), ele mesmo um gêmeo, relata sobre os Kaxinawá do leste do Peru:

Gêmeos, dizem eles, são produzidos quando um espírito engravida uma mulher. São, portanto, chamados yushin bake, "crianças-espírito", e são destruídas ao nascer. Quando eles finalmente entenderam que eu estava dizendo que eu era gêmeo, eles imediatamente se afastaram e me evitaram por muitos dias, até que o líder decidiu que eu não podia ser uma criança-espírito porque eu era muito burro e incompetente na floresta. O filho de um espírito jamais poderia ser assim.

De acordo com os Kaxinawá, que falam a língua pano, as mulheres podem ser fecundadas por espíritos ao caminharem na floresta ou à beira do rio, ou por terem sido visitadas por espíritos em seus sonhos (Lagrou 2007:225). Crianças que nascem de tais uniões são propensas a anomalias e deformidades, já que os espíritos yushin são associados com o excesso e a mutabilidade. Más-formações são vistas, portanto, como um sinal de se tratar de uma "criança-espírito".

Alguns povos da Amazônia asseveram que a quebra de tabus por um dos pais pode também levar ao nascimento de crianças que, embora sejam pessoas, não são inteiramente humanas. Os Mehinaku atribuem o nascimento de gêmeos, ou de crianças excessivamente grandes, à promiscuidade da mãe (Gregor 1987:89). Eles acreditam que as crianças são concebidas e vão crescendo pelo acúmulo de sêmen de um ou mais machos no ventre da mãe. No entanto, assim como pouca atividade sexual pode levar ao nascimento de uma criança fraca, o excesso de atividade sexual pode produzir uma criança monstruosa. Quando isso acontece, a criança não humana pode ser enterrada viva. Os Desana, que falam tukano, afirmam que gêmeos nascem quando seus pais misturam comidas masculinas e femininas, cuja combinação é tabu (Reichel-Dolmatoff 1971:235-236). Eles associam essa transgressão ao adultério e, por extensão, à endogamia incestuosa. O nascimento de gêmeos é, assim, concebido como uma ameaça tanto à humanidade quanto à vida social e, por isso, não é permitido que vivam.

Em outras sociedades indígenas da Amazônia as noções acima convergem, sendo os gêmeos considerados o resultado tanto da violação de tabus importantes quanto o ataque de seres espirituais. Os Tenetehara têm fortes tabus em relação a matar e a comer animais considerados tapiwára ou "portadores de espírito" (Wagley \& Galvão 1949:64-65). Se o pai ou a mãe 
matassem ou comessem qualquer um desses animais, o espírito do animal entraria no feto, fazendo com que desenvolvesse traços indesejáveis, como os dos animais. Bebês nascidos com tais feições não humanas, mesmo que de resto parecessem humanos, eram enterrados imediatamente, pois se pensava lhes faltarem as capacidades de verdadeiros seres humanos.

O infanticídio pode também ser praticado em casos de transgressões sociais, como crianças nascidas fora do casamento (Harner 1973:85; Conklin 2001:128; Stearman 1989:90), ou fruto de relações adúlteras (Murphy \& Murphy 1985:192). Essas crianças não são consideradas pessoas de verdade, não em função de sua filiação não humana, mas por sua falta de conexões sociais adequadas. Como veremos adiante, a constituição de pessoas de verdade requer a participação ativa e a contribuição de pais, parentes próximos e amigos. Quando essas relações estão ausentes, a pessoalidade propriamente social nunca poderá ser conseguida de forma plena.

\section{A constituição e a reconstituição de pessoas humanas}

Somente depois de se certificarem de que um recém-nascido é indubitavelmente humano, os pais ou parentes reconhecem a sua existência e se dispõem a se responsabilizar por ele. Isto é comumente feito ao apanhar o pequeno do chão, como acontece com os Suyá (Seeger 1981:151), ao dar-lhe de mamar, como com os Wari' (Conklin 2001:128), ou ao praticar a couvade, como entre os Huaorani (Rival 1998:627). Em algumas sociedades ameríndias, tais como a dos Matis, a parteira é quem deve apanhar a criança e, nesse caso, é dela a responsabilidade de estabelecer a humanidade da criança, bem como se deverá viver (Erikson 1999:296).

A averiguação da natureza humana de um recém-nascido por seus pais, parentes ou amigos não transforma automaticamente, contudo, a criança em uma pessoa completamente humana. Mesmo quando reconhecidos como humanos, a natureza dos recém-nascidos ainda é considerada indiferenciada e mutável. Nus e sem adornos, eles compartilham muitas feições com animais e outras pessoas não humanas. Eles habitam um tempo-espaço liminar no qual seus corpos e suas almas maleáveis são tidos como muito vulneráveis a ataques de seres não humanos que querem transformá-los em um deles de forma a aumentar suas próprias fileiras. Na economia política ameríndia da vida, o nascimento de uma criança humana é visto por muitos seres anteriormente humanos como um revés para a sua própria espécie.

Para evitar que seres não humanos transformem o recém-nascido em um deles, os pais humanos devem se apressar em marcar seus bebês como 
pessoas verdadeiramente humanas. Isto é ilustrado com clareza na descrição de Irving Goldman (1963:168) sobre o que as mães cubeo fazem imediatamente depois do nascimento de seu bebê:

Quando a mãe traz o filho recém-nascido para a maloca numa cesta de mandioca forrada com pano [...] Ela se põe imediatamente a lavá-lo em água morna, limpando seu corpo. Ela então pinta o rosto do pequeno com pintas vermelhas para que pareça um filhote de jaguar, e o resto do seu corpo ela pinta com o mesmo pigmento vermelho. Os pontos protegerão o bebê do jaguar, ao passo que o pigmento vermelho no rosto, comum em cerimônias de adornamento, dá de imediato ao bebê o status humano. Por fim, ela amarra cordas nos pulsos do bebê, para que seus braços cresçam fortes. Tendo feito essas coisas, a mãe apresenta a criança à sua avó, sogra da mãe, e vai para a sua maloca.

Ao pintarem o recém-nascido com pintas de jaguar, os Cubeo da região do Vaupés colombiano têm a intenção de enganar os jaguares, fazendo com que pensem que o bebê é da espécie deles. Isto deve evitar seus ataques, que podem ser letais, já que se acredita que os jaguares são feiticeiros malvados (Goldman 1963:224). Por outro lado, ao pintar o corpo do bebê com pasta vermelha de urucum, a tinta cerimonial por excelência, a mãe faz uma declaração pública em relação ao status humano da sua criança.

O processo de tornar o recém-nascido uma pessoa humana de verdade não para por aí, entretanto. Depois do nascimento de uma criança cubeo, seus pais começam um período de três dias de isolamento, durante o qual devem respeitar uma série de tabus para garantir a humanidade e a segurança do recém-nascido. Apenas então a criança será vista como alguém que se tornou uma pessoa completamente humana. No entanto, até que receba um nome, o que pode acontecer até um ano depois do seu nascimento, ela não será considerada como um membro do clã de seu pai, só então obtendo seu pleno status social de pessoa (Goldman 1963:171; ver também Crocker 1985:49). O processo de se tornar uma pessoa humana é, portanto, um processo social que envolve a contribuição não apenas dos pais, mas também de parentes próximos e amigos por meio de seus presentes de comida, ornamentos e conhecimento ritual. A humanidade é o resultado do parentesco e pessoas humanas são "dividuals", isto é, são "construídos como o lugar plural e complexo de relacionamentos que os produzem" (Strathern 1988:13). Por este motivo, o processo de se tornar uma pessoa humana é tarefa infindável. Não apenas todos os seres humanos reclamam seu status humano, como também a humanidade é uma condição instável, permanentemente contestada; algo pelo que se deve lutar, como Vilaça (2005) tão persuasivamente argumentou. 
Pode-se então dizer que pessoas humanas estão sempre no processo de se constituir. Elas não conquistam automaticamente o status de serem humanas e uma pessoa depois do nascimento e, como argumentarei, elas podem deixar de ser humanas ou pessoas em qualquer momento de suas vidas.

\section{As consequências indesejáveis da perda da alma}

No pensamento ameríndio, a conexão entre corpo e alma é no mínimo tênue e no máximo altamente instável. Este último é particularmente verdadeiro no que se refere às crianças e aos idosos, cujas almas estão fracamente apegadas aos corpos dos seus donos e, portanto, propensas a deixá-los ao mais leve abalo. A separação entre corpo e alma - o componente espiritual apartável do eu - não é uma ocorrência incomum. Como observou Gerald Weiss (1975:427) em sua obra sobre os Ashaninka (Campa) do leste do Peru, que falam o arawak, os ameríndios quase sempre relacionam o sonhar a perambulações noturnas da alma desencarnada de uma pessoa:

Segundo os meus informantes, ao dormir, a alma pode sair do corpo, e por esse motivo sonhamos... Havia consenso generalizado de que apenas uma parte da alma deixa o corpo ao dormir, já que, se a alma saísse inteiramente, o indivíduo começaria a adoecer. A saída da alma inteira do corpo, como quando é levada por um demônio, é entendida como causa não de morte instantânea, mas de doença que leva à morte, já que o corpo, subtraído de sua alma, cai em um torpor e deixa de comer. Se a alma retorna antes da chegada da morte, como quando um xamã envia a sua própria alma para recuperá-la, o indivíduo volta a ter saúde.

O desligamento temporário da alma que ocorre ao se sonhar não é perigoso em si mesmo. Ele passa a sê-lo, como sugere Weiss, apenas quando a alma perambulante é incapaz de se reunir com o corpo do seu dono.

Isto pode acontecer por uma série de razões. As almas de crianças são geralmente inclinadas a seguir suas mães ou pais quando elas vão trabalhar nos jardins ou na floresta. Ao segui-los, a alma da criança pode se perder e não conseguir encontrar o caminho de volta para casa. Crianças também são propensas a perder suas almas como resultado de um susto repentino ou pesar prolongado, emoções fortes que perturbam sua conexão corpo-alma. Nessas ocasiões, algum dentre muitos especialistas xamanísticos pode ser chamado a trazer de volta a alma perdida. Os xamãs fazem isso cantando canções para chamar almas (Santos-Granero 1984), ou partindo em expedições de alma para recuperar aquela que se encontra errante (Weiss 1975:427). 
Os indígenas amazônicos frequentemente atribuem doenças ao roubo da alma de uma pessoa - ou partes de sua alma — por um conjunto de seres espirituais. Estes podem assumir a forma de um objeto pessoal, como é o caso entre os Bororo (Crocker 1985:217). Animados em função do contato prolongado com o seu dono, esses objetos pessoais podem se tornar, de fato, extensões dos corpos de seus donos (Santos-Granero 2009b:109). Ao levarem embora algo da posse de um indivíduo, os espíritos malignos roubam uma parte da sua alma. Ainda que essa perda não provoque a morte de imediato, ela afeta a integridade do indivíduo acometido, privando-o de capacidades sensoriais, conhecimento, habilidades e afetando a sua caracterização como pessoa humana.

A perda da alma é o primeiro passo rumo à desconstituição de uma pessoa. Desprovidos de suas almas, os aflitos vagueiam como mortos-vivos. Eles vão definhando até que deixam de comer e falar, sinais inequívocos de que suas almas os abandonaram de vez e sua morte é iminente. Pessoas que chegam a este ponto são comumente abandonadas para morrer. Isto não é surpreendente dado que, do ponto de vista indígena amazônico, o que define uma pessoa é a posse de uma alma. É a alma que dota os seres de ânimo, ou seja, da capacidade de comunicar-se e da vontade de viver (Basso 1985:65; Descola 1996b:375). Quando uma pessoa doente se recusa a comer ou a falar, isto é visto não apenas como um sinal inequívoco de sua perda de ânimo (alma), mas sobretudo como uma indicação de seu avançado estágio de desconstituição como pessoa humana verdadeira.

\section{Os perigos das perspectivas oscilantes}

O status humano é tão frágil e instável quanto a condição de ser uma pessoa. Se o desconstituir-se de uma pessoa é geralmente atribuído à perda da alma, a perda da humanidade é sempre entendida como uma mudança de perspectiva por meio do contato espiritual próximo com pessoas não humanas perigosas. Francis Huxley (1957:180) oferece um vívido relato dos efeitos de um encontro como esse entre um homem urubu e um anyang, espírito dos mortos:

Antonio-hu contou-me sobre uma época, muitos anos atrás, em que havia uma horda de anyangs no rio Capim...; eles atacaram uma família lá, sequestraram uma criança pequena e estavam quase partindo com ela quando o pai agarrou um chifre e soprou nele. Isso assustou os anyangs de tal maneira que eles largaram a criança e correram uivando para dentro da selva... Algumas 
semanas depois, o pai estava caçando na selva quando foi atacado pela horda de anyangs, que comeram sua alma e o transformaram em um deles. Por um ano ele vagou pela selva, alimentando-se de frutas silvestres; bastante burro, seu cabelo comprido e embaraçado, sua pele ficando verde com a terra. Seu paradeiro foi afinal descoberto magicamente por um xamã, que o curou com fumaça de tabaco e lhe disse que ele ficaria bem se nunca mais se pintasse. Mas sua mulher queria que ele ficasse bonito numa cauin [festa com bebidas], e colocou urucum em seu rosto: ele morreu quase de imediato.

Anyang é um dos seres espirituais mais temidos pelos Urubu, de língua tupi, do leste do Brasil. São sombras errantes, almas desencarnadas de pessoas mortas que, por diversos motivos, permaneceram na terra, ressentidos e incansáveis, para assombrar os vivos. Na narrativa de Huxley, diz-se que os anyangs "comeram a alma" do homem urubu, sugerindo com isto que se tratava de um caso de perda da alma. No entanto, o narrador acrescenta que, ao comerem a sua alma, os anyangs "o transformaram em um deles". Como vimos, a perda da alma leva à morte, sendo ela mais ou menos imediata. Isto não foi o que aconteceu com o homem urubu, que viveu por muito tempo após o seu encontro com os anyangs. Huxley fornece a chave para entender esta narrativa quando argumenta que a sombra ou a alma de todo ser humano está numa relação específica de parentesco com Maír, o sol mítico e herói cultural dos Urubu. Quando a alma de uma pessoa "encontra um fantasma que é forte demais para ela, a alma perde o seu senso de parentesco e é 'comida'" (Huxley 1957:181).

Nos dias de hoje, e à luz do que sabemos acerca do perspectivismo ameríndio, diríamos que como resultado do contato espiritual próximo com os poderosos anyangs, a alma do homem perdeu a sua perspectiva humana, adquirindo a dos seus raptores. Este é um conceito ameríndio muito difundido. Os Wauja da região do Alto Xingu entendem a doença como uma mudança de perspectiva resultante da captura de porções da alma de uma pessoa por espíritos que, ao alimentarem a alma capturada com comida animal, a transformam em um deles (Barcelos Neto 2009:130). Como ficou expresso pela história acima, entre os Urubu, acredita-se que tal mudança de perspectiva se manifesta também no nível físico.

A perda do status humano não é, contudo, totalmente irreversível. A narrativa indica que o xamã curou o homem com fumaça de tabaco, a substância máxima cultural, usada frequentemente em ritos de passagem para a constituição de pessoas humanas (ver, por exemplo, Londoño Sulkin 2005:11). Por este meio ele restaurou algo como a humanidade do homem, que fora transformado, como disseram, em um morto-vivo. É por este motivo 
que o xamã diz ao homem raptado que, se ele quer continuar a viver, ele deve deixar de se pintar. Por causa de sua conexão simbólica com o sangue, os Urubu consideram a tinta vermelha de urucum uma substância vivificadora. Pessoas em períodos de isolamento, que são parte de rituais de iniciação, estão proibidas de pintar seus rostos e corpos com urucum. Considera-se que eles estão simbolicamente mortos e que se pintar com urucum seria, de acordo com Huxley (1957:180), "nocivo como tomar veneno". Ao ceder ao pedido da mulher e se pintar com tinta de urucum, o homem urubu colocou em perigo a humanidade que lhe restava, perdendo com isso sua vida.

\section{A incorporação da diferença}

Ser um "verdadeiro" humano acarreta, da perspectiva indígena amazônica, a obediência a um conjunto de expectativas morais, sociais e culturais. No contexto altamente etnocêntrico ameríndio, em que apenas as pessoas consideradas "pessoas de verdade" são as que pertencem à própria coletividade, pessoalidade e identidade são uma única coisa. Nessas sociedades, as regras para casamento e residência, as idiossincrasias linguísticas, os padrões de subsistência e culinária, os códigos de vestimenta e ornamento, bem como os hábitos de rituais e cerimônias, passam a ser indicadores cruciais para a definição de filiação étnica e pessoalidade humana. Por outro lado, os indígenas da Amazônia concebem que o eu e a identidade apenas são possíveis por meio da permanente incorporação da diferença e de diferentes outros, geralmente concebidos como afins perigosos (Overing 1977, 1983-1984; mas também Vilaça 2002 e Fausto 2007).

A condição para se tornar membro de uma dada coletividade e ao mesmo tempo um ser humano propriamente dito é sempre determinada pela consubstanciação, seja por meio da filiação e do compartilhamento físico de substâncias - sêmen, sangue menstrual, leite materno, suor — com os pais, ou por meio da comensalidade, co-residência e compartilhamento de substâncias no convívio com família, parentes, amigos e vizinhos, como argumenta de forma tão entusiástica George Mentore (2005:86) em relação aos Waiwai do interior da Guiana:

Os Waiwai dizem que viver com outras pessoas numa aldeia específica por um período considerável de tempo fará com que um indivíduo não apenas adquira o cheiro, mas também o aspecto das pessoas com quem ele ou ela vive. Isto acontece porque espaço e tempo promovem as trocas necessárias de substâncias entre corpos que permitirão que exista a vida na comunidade. Comida, 
fluidos, conversas e ideias compartilhadas ajudam na produção diária de vida comunitária e a própria qualidade e as características do ser individual. Todas as substâncias compartilhadas carregam elementos de ekatï [espiritualidade vital]. Do ponto de vista dos Waiwai, os circuitos flexíveis e os ritmos materiais das trocas diárias de fato ajudam a estabilizar as vitalidades espirituais voláteis que constituem a força que sustenta a vida do corpo.

O compartilhamento de substâncias ao longo do convívio contribui para a constituição de pessoas verdadeiras de duas maneiras: por um lado, ao eliminar as diferenças entre pessoas de dentro e de fora — os afins perigosos - gerando uma comunidade de interesse entre pessoas a princípio diferentes; por outro lado, ao estabilizar as almas altamente oscilantes e frouxamente vinculadas dos membros da coletividade de forma a preservar sua pessoalidade humana.

A consubstanciação é central não apenas para a constituição de seres humanos propriamente ditos, mas também para a sua desconstituição. Acredita-se que o compartilhamento de substâncias com outros radicais, sejam eles humanos (gente branca) ou não humanos (animais, espíritos), leve inevitavelmente a mudanças drásticas de identidade como resultado da alteração de perspectivas. A transformação de humanos em animais em função do convívio prolongado é um tema muito difundido na mitologia indígena amazônica (Rosengren 2006:87; Werlang 2006:106). Em períodos mais recentes, diversos autores têm interpretado a adoção por nativos de itens e práticas culturais dos brancos — em particular, roupas dos brancos - como indicação de um processo semelhante de incorporação (Kelly 2005; Gow 2007a, 2007b; Vilaça 2006, 2007; Lasmar 2005; Santos-Granero 2009c). Vilaça (2006:506) associa estes dois temas - incorporação e perspectivas oscilantes - ao asseverar que, assim como os xamãs wari' adotam roupas de animais para experimentar uma perspectiva animal, obtendo com isto conhecimentos privilegiados para suas atividades de cura ou feitiçaria, o povo Wari' adotou roupas dos brancos para adquirir uma percepção do mundo de seus mais poderosos outros, bem como para ter acesso ao seu saber e aos seus bens extraordinários.

Uma mudança como esta de perspectiva acarreta alterações importantes de identidade, que operam no nível corpóreo e se manifestam como mudanças de afetos ou hábitos (Viveiros de Castro 1998). Nesse sentido, atualmente, muitos indígenas da Amazônia reivindicam ser parcialmente brancos (ver, por exemplo, Turner 1992:8). A sua transformação, entretanto, nunca é total, em parte porque os indígenas da Amazônia rejeitam abertamente a ideia de se tornarem completamente brancos, povo que consideram 
ganancioso, rabugento e agressivo, e em parte porque eles julgam impossível tal transformação (Lasmar 2005:194). Transformações de identidade — sempre efetuadas na chave da incorporação - nunca são, portanto, completas. Existe um componente físico de identidade — resultante das substâncias trazidas pelos pais - que se acredita ser indelével, enquanto as mudanças na dimensão dos afetos e hábitos da identidade são sempre reversíveis, contanto que a pessoa transformada retome o modo de vida indígena.

\section{O trailer de Hakani}

As noções acima não são remanescências exóticas de um passado remoto. Elas continuam a informar e a moldar as vidas cotidianas de povos indígenas por toda a bacia amazônica. Sua persistência em situações pós-coloniais não se dá, contudo, sem problemas. Vistas como "pré-modernas", estas percepções indígenas estão em permanente rota de colisão em relação às visões dominantes, "modernas", de humanidade e pessoalidade como condições absolutas, irredutíveis e isomórficas. Uma dessas colisões aconteceu, como vimos, em maio de 2008 com o aparecimento no YouTube do trailer de Hakani, denunciando o infanticídio indígena na Amazônia e apoiando o Projeto de Lei Muwaji como forma de penalizar esta prática.

O vídeo motivou uma rápida declaração pública de Stephen Corry (2008), diretor da ONG Survival International, dedicada a defender os direitos dos povos tribais. Corry acusou os idealizadores do trailer de ludibriarem os espectadores ao apresentarem as imagens como se fossem reais, quando na verdade elas eram encenadas por atores pagos pertencentes a diversos grupos indígenas da Amazônia. Ele também acusou os cineastas de omitirem o fato de que o filme foi produzido por Jovens Com Uma Missão, uma das maiores organizações evangélicas do mundo, cuja base brasileira foi banida de vários lugares do Brasil. Por mais que se aceite que o infanticídio ainda seja praticado por alguns povos indígenas amazônicos - o que de fato ocorre, acrescentou ele, em todo o mundo - Corry argumentou que hoje em dia é uma ocorrência rara e, quando acontece, é sempre como resultado de uma decisão pessoal - geralmente secreta - e nunca, como representado no filme, como o resultado de uma imposição coletiva. Ele acrescentou que tais decisões jamais são tomadas de maneira leviana e são sempre encaradas como eventualidades trágicas. Corry conclui que, ao retratar o infanticídio indígena como uma prática rotineira, o filme "instiga sentimentos de ódio contra os índios", ao passo que, ao penalizar essa prática, a Lei Muwaji abre caminho para uma caça às bruxas em larga escala. 
Respondendo a essas acusações, a página Hakani na internet contra-argumentava que o filme nunca pretendeu retratar eventos reais, mas pertence ao gênero do docudrama e, como tal, consiste numa "representação baseada em fatos e eventos reais" (Hakani 2008). Reconhecia que o filme tinha sido produzido com o apoio de Jovens Com Uma Missão, mas negou que a ATINI — Voz Pela Vida tivesse qualquer filiação religiosa em particular. O que deixou de dizer foi que o diretor da ATINI, Edson Suzuki, é um pastor evangélico que pertence a Jovens Com Uma Missão (ver http://www.direito2.com.br/acam/2005/dez/14/sem-acordo-funai-e-missaojocum-trocam-acusacoes), e que o deputado federal Henrique Afonso, que apoia a Lei Muwaji, é um membro ativo da Frente Parlamentar Evangélica (http://liberdadedeexpressao. multiply.com/journal/item/335).

Disponibilizado no YouTube em diferentes versões e por diferentes usuários (ver, por exemplo, Greendomo 2008), até agosto de 2009 o trailer de Hakani tinha sido acessado por mais de 400.000 pessoas. Todas essas versões geraram uma discussão intensa. Aqui me concentrarei nos 178 comentários motivados pelo trailer disponibilizado por Andreabrasil 31, desde que foi postado no dia 5 de maio de 2008 até a época em que comecei a escrever este artigo, em junho de 2009. Esses comentários podem ser divididos em dois grupos. Os comentadores no primeiro grupo abordaram o problema pela perspectiva dos direitos humanos. Ajuran7 escreveu: "Eu pensei que os direitos humanos eram valorizados por todos os seres humanos. Como pode um humano negar ao outro seus direitos básicos?". David79k acrescentou: "Toda criança tem o direito a viver!!! Onde está o Human Rights Watch [entidade protetora dos direitos humanos]? O Brasil tem algum direito humano?". Annasue04 comentou: "Eles são humanos também, não importa a sua ascendência ou prática. Por que o Brasil não pode reconhecer isso e apoiar esta mudança?". Em resposta àqueles que argumentaram que o vídeo era falso, um comentador, Advasive, contestou: "Sendo ou não falso, é basicamente equivalente à tortura e à morte de crianças". Outro completou: "Você pode fazer parte de uma tribo se você quiser, mas essa tribo precisa seguir as regras de direitos humanos, caramba!" (Venooomq).

Para as pessoas neste grupo não havia dúvida de que, apesar de diferenças de filiação étnica e práticas culturais, todos os humanos são igualmente humanos e, portanto, investidos de uma série de direitos que são tanto universais quanto irrefutáveis. Akbreit reclamou: "Como é possível que essas coisas ainda estejam acontecendo? Quero dizer, não vivemos num mundo civilizado?". Sua indignação não se dirigia tanto aos povos indígenas que praticavam infanticídio, mas ao governo brasileiro, que ele percebia como não tendo agido muito para pôr um fim a essas práticas. O comentário de 
um participante brasileiro, Maksr66, que dizia que "Isso é exatamente o que o povo brasileiro está se mobilizando para mudar com a Lei Muwaji", não ajudou muito a apaziguar a indignação dos outros, talvez porque ele/ela tenha acrescentado que infelizmente "o governo não tem muito a 'ganhar' com a promulgação dessa lei", assim sugerindo que ele/ela não tinha nenhuma esperança de que a lei seria aprovada.

Um segundo grupo de pessoas abordou o problema em termos de diferenças culturais. Membros deste grupo deixavam claro que consideravam errado o infanticídio. Entretanto, eles argumentavam que, antes de condenarem o infanticídio indígena da Amazônia, as pessoas deveriam se informar melhor sobre o contexto cultural que o explica. Trabajibiri destacou que as causas para o infanticídio são econômicas; é praticado no caso de crianças incapacitadas, que "podem comer, mas não caçar" e que são, por isso, incapazes de se sustentar. Outro comentador observou que o infanticídio era um meio de controle populacional "porque seus recursos são limitados (Emancoy). Desenvolvendo isto, Armbuster1951 escreveu: "A razão é puramente a sobrevivência da tribo. Aqueles que não podem contribuir com a tribo subtraem dela, por isso, precisam ser removidos para o aperfeiçoamento da tribo". Apenas um comentador, Mortifera90, proferiu um motivo não econômico para essa prática. Ela escreveu: "Eles os enterram porque eles pensam que as crianças que têm qualquer incapacidade estão obcecadas [sic: possuídas?] por espíritos malignos e a única maneira de afastá-los é enterrando-os vivos".

Os defensores de direitos culturais davam muita importância ao relativismo cultural e pediam mais tolerância. Shamroque13 escreveu: "Quem é qualquer um de nós para dizer a eles que o que eles estão fazendo é errado? Não conhecemos seus costumes e rituais. Não sabemos como a sociedade deles funciona". Outro afirmou: "Só porque as pessoas não compartilham moral e valores ocidentais não significa que estão errados" (Anonymourryna). Muitos argumentaram que, dada a longa lista de crimes e atrocidades cometidos nas sociedades ocidentais, os ocidentais não deveriam ser tão rápidos na condenação aos indígenas da Amazônia por suas práticas culturais. "Tem coisa muito pior acontecendo no quintal da nossa casa", escreveu Gezzalinko666. Interessante observar que apenas três comentadores compararam o infanticídio indígena na Amazônia ao aborto. O assunto não foi desenvolvido por outros, sugerindo que os espectadores não viram paralelos entre os dois casos, ou seja, como as considerações culturais sobre pessoalidade e humanidade tornam aceitável ou não pôr fim à vida de um ser: em um caso, um feto; no outro, um recém-nascido. A posição dos membros deste grupo foi bem sintetizada por Tkiitt, que escreveu: "Os ocidentais deveriam tolerar outras culturas. Por que as nossas leis e os costumes deveriam ser melhores do que os deles?". 
Os defensores da universalidade dos direitos humanos rejeitaram sumariamente a ideia de que diferenças culturais poderiam servir de justificativa para práticas como o infanticídio. Abbee2828 escreveu: "É tão absurdo pensar que as pessoas podem defender o infanticídio com base no respeito cultural... Os que defendem o infanticídio também defenderiam o Holocausto, ou a circuncisão feminina etc.?". Nicolahairam concordou, argumentando: "Matar uma criança por ser diferente é errado, por isso a interferência deveria ser permitida. [...] Assassinato é assassinato. Não tem nada a ver com cultura". Caiofons condenou aqueles que defendem o direito à diferença cultural em função do que ele chamou de "relativismo moral", enquanto Satorian caracterizou-os como "esquerdistas iludidos" que "defendem a ideia de, por serem primitivos, serem todos bons!!!". Ele concluiu reforçando que "Os Direitos Universais do Homem são a cultura que temos que defender!!!", comentário que sintetiza a posição das pessoas neste grupo.

Embora, em termos gerais, a discussão gerada pelo trailer de Hakani tenha sido caracterizada como um confronto entre defensores dos direitos humanos e defensores do direito à diferença cultural, não tardou em se transformar em um debate entre defensores e oponentes do trabalho missionário, algumas vezes posto como oposição entre cristãos e ateus e, em outras, entre pessoas de direita e de esquerda. Como veremos abaixo, o debate gerado no Brasil pelo Projeto de Lei 1057, ou Lei Muwaji, seguiu um caminho semelhante.

\section{A Lei Muwaji}

Embora tenha começado como um confronto entre defensores dos direitos humanos e defensores dos direitos culturais dos povos indígenas, o debate em torno da Lei Muwaji logo se tornou uma batalha contrapondo as igrejas evangélicas e a Igreja Católica dominante, em aliança temporária com a ABA - Associação Brasileira de Antropologia. A análise dos textos e das declarações produzidos pelos diferentes grupos que participaram do debate espelha, em nível mais intelectualizado, o mesmo tipo de percepções e argumentos mobilizados pelos espectadores do YouTube.

A versão original da Lei Muwaji, apresentada pelo deputado federal Afonso e apoiada por líderes indígenas evangélicos, procura penalizar todos aqueles que cometem infanticídio e outras práticas indígenas nocivas, como abuso sexual e maus-tratos a crianças, bem como aqueles que deixam de informar às autoridades esses crimes ou que não tomam as medidas apropriadas, uma vez cientes desses crimes (Afonso 2007). Ela também propõe que crianças com risco de infanticídio ou outras práticas danosas sejam 
retiradas de suas famílias e aldeias, colocadas em abrigos administrados por agências governamentais ou não governamentais e entregues para adoção por famílias indígenas ou não indígenas. Por fim, estabelece que as práticas indígenas nocivas sejam erradicadas por meio do diálogo e da educação em direitos humanos. A proposta é cuidadosa ao declarar que respeita e fomenta as práticas indígenas tradicionais, mas "sempre que as mesmas estejam em conformidade com os direitos humanos fundamentais, estabelecidos na Constituição Federal e internacionalmente reconhecidos".

Os autores do texto legitimam a proposta ao argumentarem que ela busca a conformidade com a Constituição Federal de 1988 (Art. 227), o Estatuto da Criança e do Adolescente de 1990 (Art. $7^{\circ}$ ) e a Convenção sobre os Direitos da Criança de 1990 (Art. $6^{\circ}$ ), da qual o Brasil é signatário, que estabelecem que toda criança tem o direito inerente à vida. Além disso, eles citam os Artigos $1^{\circ}$ e $2^{\circ}$ do Código Civil Brasileiro, os quais determinam que todas as pessoas são capazes de direitos e deveres civis e que a "personalidade civil" da pessoa começa imediatamente depois do nascimento. A proposta termina com uma ardorosa defesa dos direitos humanos em detrimento do direito à diferença cultural, argumentando que "A cultura não é o bem maior a ser tutelado, mas sim o ser humano [...]. Portanto, a tolerância (no sentido de aceitação, reconhecimento da legitimidade) em relação à diversidade cultural deve ser norteada pelo respeito aos direitos humanos".

Em maio de 2007, o Projeto de Lei passou para a Comissão de Direitos Humanos e Minorias (CDHM) para revisão. A despeito das progressivas pressões para aprovar a proposta por parte de um setor do público influenciado pelo filme Hakani e pela enxurrada de notícias negativas nos jornais nacionais e regionais, a Comissão se absteve por mais de um ano de emitir uma resolução. No dia 17 de julho de 2008, entretanto, depois de uma série de passeatas em apoio à proposta em diversas cidades brasileiras, a relatora da CDHM, deputada federal Janete Pietá, finalmente emitiu um relatório recomendando a aprovação da Lei Muwaji com modificações (Pietá 2008). A proposta alternativa demandava uma ampliação do Artigo 54 do Estatuto do Índio de 1973, no qual se determina que "Os índios têm direito aos meios de proteção à saúde facultados à comunhão nacional". A proposta de acréscimo incorporava do original o seu primeiro artigo, afirmando que o Estado respeita as práticas da tradição indígena desde que estejam em conformidade com a Constituição Federal e os tratados e as convenções internacionais assinados pelo Brasil. Acrescenta então um parágrafo indicando que é atribuição dos órgãos responsáveis pelas políticas indigenistas oferecerem aos povos indígenas, entre os quais o infanticídio e outras práticas nocivas tenham sido verificados por estudos antropológicos, oportunidades amplas de adquirirem 
conhecimentos sobre a sociedade nacional. Como não criminaliza os pais pela morte de crianças mental ou fisicamente incapacitadas, a nova redação foi entendida pela ATINI e pelos defensores da Lei Muwaji como desvantajosa. Não obstante, continuaram a fazer campanha pela sua aprovação.

Opositores da lei original e de sua versão modificada alegavam que, ao se colocar o infanticídio - que, em algumas sociedades indígenas da Amazônia e sob certas circunstâncias muito específicas é uma prática aprovada no mesmo saco que abuso sexual e maus-tratos a crianças - que não são práticas, sendo fortemente rejeitadas pelos povos indígenas - a proposta criminaliza os povos indígenas, reforçando a noção de que são irracionais e selvagens. Quando, depois de muita negociação, a versão modificada da Lei Muwaji foi posta em pauta, em 24 de junho de 2009, a votação foi adiada por um pedido de vista do deputado federal Chico Alencar (Suzuki 2009). Quando pressionado a explicar sua posição, Alencar respondeu que pedira o adiamento atendendo a um pedido da Associação Brasileira de Antropologia (ABA), da Conferência Nacional dos Bispos do Brasil (CNBB) e do Conselho Indigenista Missionário (CIMI).

A posição do CIMI — e, por extensão, a do CNBB, de que faz parte - se fez clara pouco depois de a Lei Muwaji ser submetida ao Congresso Federal em 2007. Perguntado sobre o que pensava sobre o infanticídio indígena na Amazônia e a tentativa de combatê-lo por vias legais, Francisco Loebens, coordenador regional do CIMI, declarou que era contra a intervenção do Estado em assuntos culturais indígenas, já que essas intervenções geram mais problemas do que soluções (Santos 2009). "Não é uma questão de assistência médica ou psicológica - ele alegava — mas de visões de mundo diferentes. O diálogo fundamentado no conhecimento e no respeito ao outro seria uma opção melhor, porque certamente nos levaria a reconhecer as nossas próprias faltas, incluindo a violência contra crianças praticada em nossa própria sociedade, ao invés de atribuí-las somente aos outros".

A ABA também se opôs à Lei Muwaji por meio de um artigo escrito por João Pacheco de Oliveira (2009), presidente da Comissão de Assuntos Indígenas da Associação. Neste artigo, Pacheco de Oliveira argumenta que a campanha comandada pela ATINI "Não é uma campanha pró-vida, mas uma tentativa de criminalização das coletividades indígenas, colocando-as na condição permanente de réus". O Projeto de Lei promove o preconceito de que os indígenas amazônicos possuem uma "natural perversão e irracionalidade". O infanticídio indígena é praticamente inexistente e, quando ocorre, normalmente acontece em resposta a um infortúnio ainda maior que afeta a criança, sua família e sua comunidade. Os indígenas da Amazônia são célebres por sua extrema preocupação quanto à formação e ao bem-estar 
de suas crianças. A proposta procura retirar dos pais indígenas a guarda de suas crianças de forma a colocá-las sob a proteção do Estado. Infelizmente, argumenta ele, o Estado brasileiro já demonstrou sua inabilidade para proteger as crianças do país, como comprovam as legiões de crianças morando nas ruas das suas cidades. Tampouco detém a perícia para resolver os problemas das coletividades que operam em contextos culturais e linguísticos muito variados. Ele assevera que "A Declaração Universal dos Direitos Humanos foi construída para proteger os direitos dos cidadãos, não para dotar os grupos sociais mais favorecidos de um instrumento de afirmação de sua superioridade moral sobre grupos excluídos ou diferentes", e finaliza o artigo com um apelo para eliminar a Lei Muwaji.

No dia 7 de julho de 2009, poucos dias depois de a votação da Lei Muwaji ter sido adiada, representantes da ABA apresentaram uma petição à deputada Janete Pietá e aos membros da Comissão de Direitos Humanos e Minorias, requerendo formalmente o arquivamento da Lei Muwaji (ABA 2009). A petição repete alguns dos argumentos presentes no artigo de Pacheco de Oliveira. O infanticídio indígena na Amazônia é raro; o Projeto de Lei fomenta o preconceito anti-indígena; marca pessoas indígenas como suspeitas permanentes e criminaliza práticas culturais indígenas. Ela propõe, no entanto, a insólita ideia - ao menos no contexto deste debate específico de que "a maneira mais eficiente de defender os direitos humanos é defender o direito à diversidade cultural e ampliar a circulação dos diversos valores que enriquecem a vida social". Os direitos humanos são mais bem atendidos quando o seu conhecimento é difundido junto às sociedades indígenas "com fundamento numa plena tradução de suas tradições cosmológicas". Os povos indígenas da Amazônia deveriam ter o direito de negociar suas discordâncias quanto ao tema das "práticas indígenas nocivas" em deliberações internas e livres, um direito garantido pela Convenção 169 da Organização Internacional do Trabalho, ratificada pelo Brasil. A petição da ABA termina com um pedido ao Congresso de que a discussão do Projeto de Lei seja adiada permanentemente, até que o assunto seja plenamente discutido pelo Conselho Nacional de Políticas Indigenistas - composto por representantes indígenas e autoridades do governo - responsável pela revisão e a atualização do Estatuto do Índio de 1973.

\section{Reflexões finais}

Nas discussões acima, defensores de direitos humanos e defensores da diversidade cultural parecem estar operando no quadro que Latour (1993:99) 
chama de Grande Divisão Exterior, ou seja, a convicção "moderna" de que os ocidentais são intrinsecamente diferentes de todos os outros povos "prémodernos", na medida em que são os únicos que distinguem claramente o domínio não humano e objetivo da Natureza e da Ciência do domínio humano e subjetivo da Cultura e da Sociedade - uma distinção chamada por ele de Grande Divisão Interior. De acordo com esta visão, ao passo que povos modernos percebem que Natureza e Sociedade, objetos e sujeitos são realidades diferentes e separadas, os pré-modernos ignoram este axioma supremo, apagando as fronteiras entre as duas esferas e unindo-as como se fossem uma mesma coisa. Latour (1993:103-104) argumenta, no entanto, que nem os ocidentais distinguem entre Natureza e Sociedade tão radicalmente quanto supõem, nem os não ocidentais fazem com que se sobreponham tanto como os ocidentais asseguram. Ele afirma que, a despeito da obsessão moderna com a "purificação" — o ato de distinguir e separar esferas ontológicas em oposições binárias - o real efeito da modernidade foi a produção de quase-objetos/quase-sujeitos híbridos e naturezas/sociedades que não são intrinsecamente diferentes daquelas produzidas por povos não ocidentais. Esses híbridos são o resultado da "mediação", o ato pelo qual, de maneira a preservar a distinção entre Natureza e Sociedade, os modernos terminam por produzir fatos socializados e humanos naturalizados (ibidem:57).

Latour (ibidem:104-105) argumenta que o relativismo cultural, assim como outras formas de relativismo, é inadequado para entender as variações culturais, por ainda ser baseado na noção de que Natureza e Sociedade são entidades separadas, e pela ideia de que aquilo que distingue as diferentes sociedades são as suas visões diferenciadas sobre a Natureza. Como vimos, ao analisarem "práticas nocivas", os relativistas podem, no máximo, propor que coisas ruins acontecem em todo lugar, tornando moral o relativismo cultural. Ao invés disso, Latour defende uma "antropologia simétrica", que não apenas abandone a distinção entre Natureza e Sociedade, mas que reconheça naturezas/sociedades como seu objeto de estudo, assim apagando a dicotomia entre modernos e pré-modernos. "A antropologia simétrica - ele afirma - deve perceber que as duas Grandes Divisões não apenas descrevem a realidade - a nossa, bem como a de outros - mas definem o modo particular como os ocidentais estabeleceram suas relações com outros, contanto que se sentissem modernos" (Latour 1993:103). Postura seguida por Gow (1997), que sugere que o parentesco deveria ser considerado como uma expressão da consciência e da linguagem humana e, assim, como um fenômeno simultaneamente biológico e sociocultural.

Quando se adota tal posição, percebe-se a extensão em que os debates desencadeados pelo filme Hakani e a Lei Muwaji se encaixam nos para- 
digmas de modernidade. Com efeito, uma análise detida do argumento de cada uma das partes envolvidas mostra que ambas dão por certa a natureza pré-moderna das práticas indígenas na Amazônia, sem tentarem entender a sua lógica - neste caso, as ideias de que pessoalidade é um atributo de todos os seres humanos, que nem todas as pessoas são humanas e que toda humanidade é uma condição instável, contestada - ignorando, ao mesmo tempo, os diversos sinais que apontam no sentido de que, nas sociedades pós-industriais, as noções de pessoalidade e humanidade não são mais tão isomórficas quanto se supunha em um passado não muito distante.

Nas poucas ocasiões em que participantes do debate arriscaram opinar sobre o motivo pelo qual os indígenas da Amazônia praticam infanticídio, a maior parte destacava razões ecológicas ou econômicas: a incapacidade de crianças deficientes se sustentarem sozinhas, o fardo representado por gêmeos para os seus pais ou a escassez de recursos que requerem alguma medida de controle populacional, ou seja, razões "objetivas" que têm uma longa tradição na antropologia. Um bom exemplo desta posição no debate acadêmico brasileiro — criticado por Soares Jardim (2010) — é o recente artigo de Ferreira Feitosa et al. (2010), no qual os autores explicam o infanticídio indígena como "forma de controle de natalidade e até mesmo mecanismo de adaptação da vida humana às condições adversas de sobrevivência em certos ambientes hostis, em especial nas condições da selva". Por outro lado, aqueles que mencionaram razões culturais, como os realizadores do filme Hakani, costumam atribuir o infanticídio à crença de que os gêmeos, assim como crianças com incapacidades mentais ou más-formações, trazem "azar". Até agosto de 2009, quando este artigo foi finalizado, o único participante que aludiu à possibilidade de o infanticídio ser associado a diferentes noções de humanidade e pessoalidade foi Corry (2008), que alegou que "Bebês não são considerados realmente membros da sociedade, de forma que não são propriamente humanos até que tenham sido 'reconhecidos', muitas vezes pela atribuição do nome, por exemplo". Depois dessa data, no entanto, alguns participantes trouxeram o ponto de vista indígena ao debate, em um esforço para trazer novas perspectivas à questão (ver, por exemplo, Marianna Holanda apud Munhoz 2010; e também Holanda 2008). Esses esforços foram ferozmente rejeitados pelos defensores da Lei Muwaji (Suzuki 2010).

Cabe ressaltar que, até o presente momento, os debatedores deixaram de ver muitas ocorrências em que pessoalidade e humanidade são percebidas como condições separadas nas sociedades ocidentais, ocorrências estas em que o pensamento ocidental se aproxima das perspectivas amazônicas. É claramente o caso do aborto em muitos países do Ocidente, onde é uma prática legal até certo ponto da gravidez. É também o caso das discussões em torno do uso 
de células embrionárias humanas na pesquisa de células-tronco. Em ambos os casos, defensores e opositores do aborto e do uso de células embrionárias não têm dúvidas de que o embrião ou feto é "humano": o que está em debate é se se trata de uma "pessoa" e, quando se torna uma pessoa, sujeito com direitos civis. Preocupações semelhantes avultam nos debates éticos sobre a clonagem de seres humanos. Essas preocupações atingiram o grande público por meio de filmes como $A$ ilha (The island), em que humanos abastados encomendam clones deles mesmos de modo a manterem ao alcance uma fonte útil de órgãos, preservados para quando houver necessidade. Ao mesmo tempo em que não se nega que os clones são humanos, eles não são reconhecidos como pessoas. Como alega um dos personagens: "Vocês não são como eu... Vocês não são pessoas de verdade. Vocês são cópias das pessoas de verdade".

O pretendido isomorfismo entre humanidade e pessoalidade também foi contestado em outros incidentes amplamente divulgados. No debate de 2009 em torno do pedido de Beppino Englaro para desconectar sua filha Eluana das máquinas que a mantiveram viva, em coma, ao longo de 17 anos, a questão que mobilizou os italianos não era se ela era humana, mas se ainda era possível considerá-la uma pessoa, tornando homicídio o ato de desconectá-la. Por outro lado, no célebre caso dos ativistas austríacos defensores dos direitos dos animais que, em fevereiro de 2007, pediram o reconhecimento legal do status de pessoa para Matthew Hiasl Pan, um chimpanzé de 26 anos que vivia no abrigo animal da Cidade Nova de Viena (Wiener Neustadt), a questão não era se Mathew era humano, algo que todos os envolvidos admitiram não ser o caso, mas se era possível considerá-lo uma pessoa e, como tal, apto a receber a herança deixada para ele por um doador generoso. No caso de uma mulher de Nova York que, em 1996, depois de ter vivido dez anos em estado vegetativo, ficou grávida depois de ter sido estuprada por um auxiliar do hospital, a questão era se, em se tratando do produto de um ato de violência exercido em uma mulher inconsciente, dever-se-ia permitir que o bebê nascesse - uma situação muito parecida com a das mulheres indígenas fecundadas por espíritos ao sonhar. A decisão dos pais da mulher em coma de ficarem com o bebê foi criticada por muitos, que pensavam que, já que o bebê não tinha sido um projeto dela, fazer com que a mulher o desse à luz - o que trazia riscos médicos relevantes - constituía abuso de seus direitos.

Por fim, a discussão gerada pela descoberta em 1998 dos restos mortais de 25.000 anos de idade da criança de Lagar Velho, que frustram as características físicas humanas modernas e neandertais, tem alimentado o que a mídia rotulou de "guerras neandertais". Os oponentes nessas guerras parecem estar de acordo quanto ao fato de que os neandertais se comportavam como pessoas, fabricando ferramentas e instrumentos musicais, 
vestindo ornamentos, usando pigmentos, possuindo um tipo incipiente de linguagem, e enterrando seus mortos com diversas oferendas; o que está em disputa é se eles pertencem à espécie Homo sapiens e se podem, portanto, ser considerados completamente humanos.

O que esses debatedores demonstram é que aquelas noções tradicionais ocidentais de humanidade e pessoalidade estão em crise e que seu suposto isomorfismo pode ser apenas um conceito moderno, o resultado de repetidos atos de purificação. Como demonstram os exemplos acima, nas sociedades ocidentais alguns humanos não são considerados pessoas, ao passo que algumas pessoas não são consideradas humanas. Esta crise conceitual é ampla e tem conotações políticas e religiosas importantes. Não está confinada ao campo rarefeito da pesquisa filosófica, mas se tornou o centro das guerras culturais que embalam as sociedades pós-industriais. Algumas vezes estas guerras se apresentam como confrontos entre povos religiosos e não religiosos; outras vezes são representadas como guerras entre liberais e conservadores. Em alguns casos, ambas as dimensões se mesclam em guerras entre grupos "pró-vida" e "pró-escolha".

Algumas vezes, todas as denominações cristãs unem forças para lutar por uma causa, como no caso do aborto ou do uso de células embrionárias. Em outras ocorrências, como no debate brasileiro sobre o infanticídio, evangélicos e católicos assumem posições antagônicas. A questão é que humanidade e pessoalidade não são noções isomórficas nem claramente definidas, como gostariam os defensores da Lei Muwaji. Elas são conceitos culturais e, por conseguinte, históricos - que não apenas variam no espaço e no tempo, mas podem estar abertos a interpretações contestatórias em situações diferentes numa mesma sociedade ou num mesmo contexto cultural. Ao invés de contribuir para um melhor conhecimento sobre as sociedades indígenas, o debate sobre o infanticídio indígena expôs, portanto, por meio de suas postulações e omissões, a extensão da fratura que afeta a noção de pessoa/humano nas sociedades ocidentais e, com ela, a profunda - mas potencialmente positiva - crise do pensamento ocidental "moderno".

Recebido em 28 de junho de 2010

Aprovado em 01 de abril de 2011

Tradução de Fernanda Guimarães

Fernando Santos-Granero é pesquisador do Instituto Smithsoniano de Pesquisa Tropical. E-mail: <santosf@si.edu> 


\section{Notas}

* Uma primeira versão deste artigo foi apresentada na Sawyer Seminar Series sobre "Saberes, formas de saber e a universidade pós-colonial" ("Knowledges, Ways of Knowing, and the Post-Colonial University"), patrocinado pela Fundação Andrew W. Mellon, idealizado por Lesley Green e acolhido pelo Departamento de Antropologia Social da Universidade da Cidade do Cabo, de 31 de julho a 16 de agosto de 2009. Sou muito grato a Lesley e aos participantes do seminário por seus comentários a respeito daquela primeira versão. Também gostaria de agradecer a Carlos Fausto, Bruna Franchetto, Els Lagrou e Aparecida Vilaça por seus comentários perspicazes a respeito da versão posterior deste artigo, bem como por me incentivarem a submetê-lo à Mana.

\section{Referências bibliográficas}

ABA. 2009. Agenda da Diretoria da Associação Brasileira de Antropologia (ABA) para audiência com componentes da Comissão de Direitos Humanos e Minorias da Câmara de Deputados. Apresentado ao Congresso Federal em 7 de julho de 2009. [http://www.abant. org.br]. Acesso em julho de 2009.

ABREU, Marcelo. 2007a. "A segunda vida de Hakani". Correio Braziliense, 03/10/07. Disponível em: http://vozpelavida-midia.blogspot. com/2007/10/correio-braziliense. html. Acessado em junho de 2009. 2007b. "O sorriso de Hakani". Correio Braziliense, 04/10/07. Disponível em: http://vozpelavida-midia.blogspot.com/2007/10/correio-braziliense. html. Acessado em junho de 2009. AFONSO, Henrique. 2007. Projeto de Lei No 1057. Submitted to Brazil"s Federal Congress by Congressman Henrique Afonso on 11 May, 2007. Disponível em: http://www.metodis- ta.org.br/index.jsp? conteudo $=6730$. Acesso em junho de 2009.

ANDREABRASIL31. 2008. "Children buried alive in the Amazon - Hakani". YouTube video uploaded May 5, 2008. Disponível em: http://www. youtube.com/watch? $\mathrm{v}=$ st $48 \mathrm{Tdd} 9 \mathrm{Sz} 4$. Acesso em julho de 2008.

BARCELOS NETO, Aristoteles. 2009. "The (de)animalization of objects: food offerings and subjectivization of masks and flutes among the Wauja of southeastern Amazonia". In: Fernando Santos-Granero (ed.), The occult life of Things: native amazonian theories of materiality and personhood. Tucson: The University of Arizona Press. pp. 128-151.

BASSO, Ellen B. 1985. A musical view of the universe: kalapalo myth and ritual performances. Philadelphia: University of Pennsylvania Press.

BROWN, Michael F. 1986. Tsewa's gift: magic and meaning in an amazonian 
society. Washington DC: Smithsonian Institution Press.

CIVRIEUX, Marc de. 1997. Watunna. An orinoco creation cycle. Austin: University of Texas Press.

CONKLIN, Beth A. 2001. Consuming grief: compassionate cannibalism in an amazonian society. Austin: University of Texas Press.

CORRY, Stephen. 2008. "Hakani: paving a road to hell". Disponível em: http://www.survival-international. org/about/hakani. Acesso em novembro de 2008 .

CROCKER, Jon Christopher. 1985. Vital souls. Bororo cosmology, natural symbolism, and shamanism. Tucson : The University of Arizona Press.

DESCOLA, Philippe. 1996a. In the society of nature. A native ecology in Amazonia. Cambridge: Cambridge University Press.

1996b. The spears of twilight: life and death in the amazon jungle. Glasgow: HarperCollins Publishers.

ERIKSON, Philippe. 1999. El sello de los antepasados. Marcado del cuerpo y demarcación étnica entre los Matis de la Amazonía. Quito: Ediciones Abya-Yala/Instituto Francés de Estudios Andinos.

FAUSTO, Carlos. 2007. "Feasting on people: eating animals and humans in Amazonia." Current Anthropology, 48(4):497-530.

FERREIRA FEITOSA, Saulo; GARRAFA, Volnei; CORNELLI, Gabriele; TARDIVO, Carla \& CARVALHO, Samuel José de. 2010. "Bioethics, culture and infanticide in brazilian indigenous communities: the Zuruahá case". Cadernos de Saúde Pública, 26(5):853-878.

GOLDMAN, Irving. 1963. The Cubeo. Indians of the northwest Amazon. Urbana: The University of Illinois Press.
GREENDOMO. 2008. "Children Buried Alive in the Amazon". YouTube video uploaded May 27, 2008. Disponível em: http://www.youtube.com/watc $\mathrm{h} ? \mathrm{p}=$ 0CE9E25AE7B07599\&playne $\mathrm{xt}=1$ \&index $=0$ \&feature $=$ PlayList $\&$ $\mathrm{v}=$ RbjRU6_Zj0U. Acesso em julho de 2008.

GREGOR, Thomas. 1987. Anxious pleasures. The sexual lives of an amazonian people. Chicago: The University of Chicago Press.

GOW, Peter. 1997. "O parentesco como consciência humana: o caso dos Piro". Mana. Estudos de Antropologia Social, 3(2):39-65.

. 2007a. "'Ex-Cocama' transforming identities in peruvian Amazonia". In: Carlos Fausto \& Michael Heckenberger (eds.), Time and memory in indigenous Amazonia. Gainesville: University Press of Florida. pp. 194-215. . 2007b. "La ropa como aculturación en la amazonía peruana". Amazonía Peruana, 15(30):283-304.

HAKANI. 2008. "Projeto Hakani: O que é real e o que não é real". Disponível em: http://www.hakani.org/pt/ news_projeto_hakani.asp. Acesso em novembro de 2008.

HARNER, Michael. 1973. The Jivaro: people of the sacred waterfalls. Garden City, NY: Anchor Press.

HOLANDA, Marianna. 2008. Quem são os humanos dos direitos? Sobre a criminalização do infanticídio indígena. Dissertação de mestrado, Departamento de Antropologia, Universidade de Brasilia.

HUXLEY, Francis. 1957. Affable savages: an anthropologist among the Urubu indians of Brazil. New York: The Viking Press.

KELLY, José Antonio. 2005. "Notas para uma teoria do 'virar branco'". Mana. Estudos de Antropologia Social, 11(1): 201-234. 
KENSINGER, Kenneth M. 1995. How real people ought to live: The Cashinahua of eastern Peru. Prospect Heights, ILL: Waveland Press.

LAGROU, Els. 2007. A fluidez da forma: arte, alteridade e agência em uma sociedade amazônica (Kaxinawa, Acre). Rio de Janeiro: Topbooks Editora.

LASMAR, Cristiane. 2005. De volta ao Lago de Leite. Gênero e transformação no Alto Rio Negro. São Paulo: Editora UNESP/ ISA; Rio de Janeiro: NUTI.

LATOUR, Bruno. 1993. We have never been modern. Translated by Catherine Porter. Cambridge: Harvard University Press.

LONDOÑO SULKIN, Carlos. 2005. "Inhuman beings: morality and perspectivism among Muinane people (Colombian Amazon)". Ethnos, 70(1):7-30.

LÓPEZ, Egleé. 2006. “Noções de corporalidade e pessoa entre os jodi". Mana. Estudos de Antropologia Social, 12(2):359-388.

MENTORE, George. 2005. Of passionate curves and desirable cadences. Themes on Waiwai social being. Lincoln \& London: University of Nebraska Press.

MUNHOZ, Fabíola. 2010. "Infanticídio: o direito da mulher indígena sob polêmica". Disponível em: http://www. amazonia.org.br/noticias/noticia. $\mathrm{cfm} ? \mathrm{id}=347765$. Acesso em junho de 2010.

MURPHY, Yolanda \& Robert F. Murphy. 1985. Women of the forest. New York. Columbia University Press.

OVERING, Joanna. 1977. "Orientation for paper topics". Acts of the 42nd International Congress of Americanistes, 2:9-10.

1983-1984. "Elementary structures of reciprocity: a comparative note on Guianese, Central Brazilian, and North-West Amazon socio-political thought." Antropológica, 59-62: 331-348.

PACHECO DE OLIVEIRA, João. 2009. "Infanticídio entre as populações indígenas. Campanha humanitária ou renovação de preconceito?" Disponível em: http://www.abant.org.br. Acesso em junho de 2009.

PIETÁ, Janete. 2008. Substitutivo ao Projeto de Lei $N^{\circ}$ 1057. Submitted to the consideration of Brazil's Federal Congress by Congresswoman Janete Pietá on 17 July, 2008. Disponível em: http://leimuwaji.blogspot.com. Acesso em junho de 2009.

REICHEL-DOLMATOFF, Gerardo. 1971. Amazonian cosmos. The sexual and religious symbolism of the Tukano indians. Chicago: The University of Chicago Press.

RIVAL, Laura. 1998. "Androgynous parents and guest children: the huaorani couvade". Journal of the Royal Anthropological Society, 4(4):619-642.

ROSENGREN, Dan. 2006. "Corporeidade matsigenka: uma realidade não biológica. Sobre noções de consciência e a constituição da identidade". In: Fernando Santos-Granero \& George Mentore (eds.), "In the world and about the world: amerindian modes of knowledge. Special issue in honor of Prof. Joanna Overing". Revista de Antropologia, 49(1):133-163.

SANTOS, Marcelo. 2009. "Bebês indígenas, marcados para morrer". Problemas Brasileiros, 381. Disponível em: http://www.sescsp.org.br/sesc/ revistas_sesc/pb/artigo.cfm?Edicao_ Id =276\&Artigo_ID =4340\&IDCatego ria $=4948 \&$ reftype $=1 \&$ BreadCrumb $=$ 1. Acesso em junho de 2009.

SANTOS-GRANERO, Fernando. 1984. "El cantar de las almas perdidas (concepciones amuesha del ser y la enfermedad)". Amazonía Indígena, 4(8): 7-10. 
1998. "Writing history into the landscape: space, myth and ritual in contemporary Amazonia". American Ethnologist, 25(2):128-148. . 2009a. Vital enemies. Slavery, predation, and the amerindian political economy of life. Austin: University of Texas Press. . 2009b. "From baby slings to feather bibles and from star utensils to jaguar stones: the multiple ways of being a thing in the yanesha lived world". In: Fernando Santos-Granero (ed.), The occult life of things: native amazonian theories of materiality and personhood. Tucson: The University of Arizona Press. pp. 105-127.

. 2009c. "Hybrid bodyscapes. Hybrid bodyscapes: a visual history of yanesha patterns of cultural change". Current Anthropology, 50(4):477-494.

SEEGER, Anthony. 1981. Nature and society in Central Brazil. The Suya indians of Mato Grosso. Cambridge, MA: Harvard University Press.

SOARES JARDIM, César. 2010. "Comments on Ferreira Feitosa et al.'s article 'Bioethics, culture and infanticide in brazilian indigenous communities: the Zuruahá case'". Cadernos de Saúde Pública, 26(5):873-874.

STEARMAN, Allyn M. 1989. Yuquí. Forest nomads in a changing world. New York: Holt, Rinehart \& Winston.

STOlZE LIMA, Tânia. 1999. "The two and its many. Reflections on perspectivism in a tupi cosmology". Ethnos, 64(1):107-31.

STRATHERN, Marilyn. 1990. The gender of the gift. Problems with women and problems with society in Melanesia. Berkeley: University of California Press.

SUZUKI, Edson \& SUZUKI, Márcia. 2009. "A lei Muwaji não passou". Email to friends. Disponível em: http://pauloeliete.blogspot.com/2009/06/lei- muwaji-nao-passou.html. Acesso em julho de 2009.

SUZUKI, Márcia. 2010. "A estranha teoria do homícidio sem morte". Disponível em: http://leimuwaji.blogspot.com. Acesso em junho de 2010.

TURNER, Terence. 1992. "Defiant images: the Kayapo appropriation of video". Anthropology Today, 8(6):5-16.

VILAÇA, Aparecida. 1992. Comendo como gente. Formas do canibalismo Wari'. Rio de Janeiro: Editora UFRJ. 2002. "Making kin out of others in Amazonia". Journal of the Royal Anthropological Institute, 8(2):347-365. . 2005. "Chronically unstable bodies: reflections on amazonian corporalities". Journal of the Royal Anthropological Institute, 11(3):445-464.

2006. Quem somos nós. Os Wari' encontram os brancos. Rio de Janeiro: Editora UFRJ.

2007. "Cultural change as body metamorphosis". In: Carlos Fausto \& Michael Heckenberger (eds.), Time and memory in indigenous Amazonia. Gainesville: University Press of Florida. pp. 194-215.

VIVEIROS DE CASTRO, Eduardo. 1998. "Cosmological deixis and amerindian perspectivism". Journal of the Royal Anthropological Institute, 4(3):469-488.

WAGLEY, Charles \& Eduardo Galvão. 1949. The Tenetehara indians of Brazil. A culture in transition. New York: Columbia University Press.

WEISS, Gerald. 1975. Campa cosmology: the world of a forest tribe in South America. New York: The American Museum of Natural History.

WERLANG, Guilherme. 2006. "De corpo e alma". In: Fernando Santos-Granero \& George Mentore (eds.), "In the world and about the world: amerindian modes of knowledge. Special issue in honor of Prof. Joanna Overing". Revista de Antropologia, 49(1):165-201. 
Resumo

O presente artigo examina o debate, desencadeado pela campanha da ONG ATINI Voz pela Vida e travado tanto no ciberespaço quanto na mídia brasileira, a respeito do infanticídio na Amazônia. Argumenta que este debate foi levado adiante em termos ocidentais — o suposto isomorfismo entre as noções de "humanidade" e "pessoa" - e, como tal, contribui pouco para entender esta incomum prática indígena. Para evitar o duplo risco do "imperialismo cultural" e do "relativismo cultural", adota um ponto de vista indígena, sustentando que os indígenas amazônicos consideram humanidade e pessoa como "estados de existência" independentes. Explora esta percepção por meio da análise de uma série de "instantâneos" etnográficos, à luz dos recentes desenvolvimentos teóricos, e conclui que, ao invés de confirmar o "primitivismo" das sociedades indígenas da Amazônia, este debate expõe a fratura da noção ocidental de "humano/pessoa", bem como a profunda - embora potencialmente positiva - crise do "moderno" pensamento ocidental.

Palavras-chave Amazônia, Ameríndios, Infanticídio, Humanidade, Pessoa
Abstract

This article examines the debate on native Amazonian infanticide triggered by the lobbying of the NGO ATINI-Voice for Life in both cyberspace and the Brazilian media. It argues that this debate has been carried out in Western terms - the supposed isomorphism between the notions of 'humanness' and 'personhood' — and, as such, contributes little to understanding this unusual indigenous practice. To avoid the dual peril of 'cultural imperialism' and 'cultural relativism,' the article adopts a native point of view. The article contends that native Amazonians consider humanness and personhood as independent 'states of being.' It explores this perception through the analysis of a series of ethnographic 'snapshots' in the light of recent theoretical developments. The author concludes that rather than confirming the 'primitiveness' of native Amazonian societies, this debate exposes the fracture of the Western notion of 'human/person,' as well as the profound - but potentially positive - crisis of 'modern' Western thought.

Key words Amazonia, Amerindians, Infanticide, Humanness, Personhood 